\title{
WILEY
}

\section{The Psychological Treatment of Insomnia}

COLIN A. ESPIE, Ravenspark Hospital, Irvine, Scotland, $U K$

This book will prove a most valuable asset because it integrates both theory and practice concerning insomnia. Readers will obtain a balanced view of the full range of psychological methods and also help with drugdependent insomniacs who present for therapy. The basic orientation of the book is practical - the author's own clinical experience with insomnia shows through.

Wiley Series in Clinical Psychology Series Editor: F.N. Watts

0471923699 272pp Jun 1991 (hbk) $£ 35.50$

$0471929824272 p p$ Jun 1991 (pbk) $£ 16.95$

\section{Clinical Child Psychology}

Social Learning, Development and Behaviour

\section{MARTIN HERBERT, University of Leicester, $U K$}

Written by one of the leading authorities on the specialization of clinical child psychology, this comprehensive introductory handbook brings together the many and diverse theories and policies that form the theory and practice of clinical child psychology in both Europe and North America.

Wiley Series in Clinical Psychology

Series Editor: F.N. Watts

0471921661 456pp Apr 1991 (hbk)

$£ 49.50$

0471929077 456pp Apr 1991 (pbk)

$£ 17.95$

JOHN WILEY \& SONS LTD

BAFFINS LANE CHICHESTER

WEST SUSSEX PO19 1UD

\section{Clinical Approaches to Sex Offenders and Their Victims}

Edited by CLIVE R. HOLLIN, University of Birmingham and Glenthorne Youth Treatment Centre, Birmingham, UK and KEVIN HOWELLS, University of Birmingham, UK

A great number of researchers and practitioners have become involved in clinical work with sex offenders and their victims. The editors have drawn together, in a single volume, up-to-date thinking, research findings, and practice relevant to both offenders and victims.

Wiley Series in Clinical Approaches to Criminal Behaviour

$0471928178336 p p$ Jan $1991 \quad £ 34.95$

Now available in paperback...

\section{Measuring Human Problems}

Edited by DAVID PECK, Highland Health Board, Scotland and COLIN SHAPIRO, Royal Edinburgh Hospital, Scolland

A practical guide to questionnaires, rating, behavioural and psychophysiological measures for monitoring human responses to psychological and psychiatric problems.

Wiley Series in Clinical Psychology Series Editor: F.N. Watts

0471934828 416pp Apr 1992 E18.95

Wiley books are available through all major booksellers. Alternatively order direct from Wiley (payment to John Wiley \& Sons Lid). Credit card orders accepted by telephone (0243) 829121 or Linkline (0800) 243407. Please note that prices quoted here apply to UK and Europe only. 


\section{Instructions to Authors}

1. Submission. Articles written in English and not submitted for publication elsewhere, should be sent to Paul Salkovskis, Editor, Bebavioural Psychotherapy, Department of Psychiatry, University of Oxford, Warneford Hospital, Oxford OX3 7JX, UK.

2. Manuscript preparation. Four complete copies of the manuscript must be submitted. Original figures should be supplied at the time of submission. Articles must be typed double-spaced throughout on standard sized paper (preferably A4) allowing wide margins all round. Where unpublished material, e.g. behaviour rating scales, therapy manuals, etc. is referred to in an article, copies should be submitted to facilitate review.

Manuscripts will be sent out for review exactly as submitted. Authors who want a blind review should mark two copies of their article "review copy" omitting from these copies details of authorship.

Abbreviations where used must be standard. The Système International (SI) should be used for all units; where metric units are used the SI equivalent must also be given. Probability values and power statistics should be given with statistic values and degrees of freedom [e.g. $F(1,34)=123.07, P<0.001]$, but such information may be included in tables rather than the main text.

Spelling must be consistent within an article, either using British usage (The Shorter Oxford English Dictionary), or American usage (Webster's New Collegiate Dictionary). However, spelling in the list of references must be literal to each original publication.

Details of style not specified here may be determined by reference to the Publication Manual of the American Psychological Association or the style manual of the British Psychological Society.

Articles should conform to the following scheme:

(a) Title page. The title should phrase concisely the major issues. Author(s) to be given with departmental affiliations and addresses, grouped appropriately. A running head of no more than 40 characters should be indicated.

(b) Summary. This should summarize the article in no more than 200 words.

(c) Text. This should begin with an introduction, succinctly introducing the point of the paper to those interested in the general area of the journal. Attention should be paid to the Editorial Statement which appears in the January and July issues at the back of the Journal. References within the text should be given in the form Jones and Smith (1973). When there are three or up to and including five authors the first citation should include all authors; subsequent citations should be given as Williams et al. (1973). Authors with the same surname should be distinguished by their initials. The approximate positions of tables and figures should be indicated in the text. Footnotes should be avoided where possible.

(d) Reference note(s). A list of all cited unpublished or limited circulation material, numbered in order of appearance in the text, giving as much information as possible about extant manuscripts.

(e) References. All citations in the text should be listed in strict alphabetical order according to surnames. Multiple references to the same author(s) should be listed chronologically, using a, b, etc., for entries within the same year. Formats for journal articles, books and chapters should follow these examples:

BECKER, M. R. and GreEN, L. W. (1975). A family approach to compliance with medical treatment: A selective review of the literature. International Journal of Health Education 18, 173-182.

THORP, R. G. and WETZEL, R. J. (1969). Behaviour Modification in the Natural Environment. New York: Academic Press.

Roskies, E. and Lazarus, R. S. (1980). Coping theory and the teaching of coping skills. In P. O. Davidson and S. M. Davidson (Eds). Behavioural Medicine: Changing Health Lifestyles. New York: Brunner/Mazel.

(f) Footnotes. The first, and preferably only, footnote will appear at the foot of the first page of each article, and subsequently may acknowledge previous unpublished presentation (e.g. dissertation, meeting paper) financial support, scholarly or technical assistance, or a change in affiliation. Its concluding (or only) paragraph must be the name and full mailing address of the author to whom reprint requests or other inquiries should be sent.

(g) Tables. Tables should be numbered and given explanatory titles.

(h) Figure captions. Numbered captions should be typed on a separate page.

(i) Figures. Original drawings or prints must be submitted for each line or half-tone illustration. Figures should be clearly labelled and be camera-ready wherever possible.

3. Proofs, Reprints and Copyright. Proofs of accepted articles will be sent to authors for the correction of printers' errors; author's alterations may be charged. Authors submitting a manuscript do so on the understanding that if it is accepted for publication exclusive copyright of the paper shall be assigned to the Association. In consideration of the assignment of copyright, 25 copies of each paper will be supplied. Further reprints may be ordered at extra cost; the reprint order form will be sent with the proofs. The publishers will not put any limitation on the personal freedom of the author to use material contained in the paper in other works. 


\section{Contents}

Jim White, Mary Keenan \& Neil Brooks

Stress Control: A Controlled Comparative Investigation of Large Group Therapy for Generalized Anxiety Disorder

Carole Sutton

Training Parents to Manage Difficult Children: A Comparison of Methods

\section{Clinical Section}

Irwin S Rosenfarb \& Jim Mintz

Assessing Social Skill in Role-Play Scenes: Is Personal Relerance Relevant?

Michael Barkham, James Moorey \& Godfrey Davis

Cognitive-Behavioural Therapy in Two-Plus-One Sessions:

A Pilot Field Trial

Vivien J Lewis, Alan J Blair \& David A Booth

Outcome of Group Therapy for Body-Image Emotionality $E$

Weight-Control Self-Efficacy'

Lee Beames, Matthew R Sanders \& William Bor

The Role of Parent Training in the Cognitive-Behavioral

Treatment of Children's Headaches

\section{Brief Clinical Reports}

Cheree Martin \& Nicholas Tarrier

The Importance of Cultural Factors in the Exposure to Obsessive

Ruminations: A Case Example

Book Reviews 